\title{
Tractable chemical models for CVD of silicon and carbon
}

\author{
E. BLANQUET ${ }^{(1)}$ and S.A. GOKOGLU
}

NASA Lewis Research Center, 21000 Brookpark Rd, Cleveland OH 44135, U.S.A.

\begin{abstract}
Tractable chemical models are validated for the CVD of silicon and carbon. Dilute silane $\left(\mathrm{SiH}_{4}\right)$ and methane $\left(\mathrm{CH}_{4}\right)$ in hydrogen are chosen as gaseous precursors. The chemical mechanism for each systems $\mathrm{Si}$ and $\mathrm{C}$ is deliberately reduced to three reactions in the models: one in the gas phase and two at the surface. The axial-flow CVD reactor utilized in this study has well-characterized flow and thermal fields and provides variable deposition rates in the axial direction. Comparisons between the experimental and calculated deposition rates are made at different pressures and temperatures.
\end{abstract}

\section{INTRODUCTION}

Chemical Vapor Deposition (CVD) is a widely used process in modern technology for the production of many electronic, optical and structural materials. Despite its increasing importance in the industry, the scientific understanding of the phenomena involved in CVD is still rather insufficient. A complete analysis of this process should include gas phase and surface chemical reaction kinetics, multicomponent mass transport, fluids mechanics and thermodynamics [1]. Many different numerical models have been developed with broad applications to the CVD process. The availability of elaborate computational fluid dynamics (CFD) codes allows accurate predictions of velocity, thermal and concentration fields in threedimensional or complex geometry reactors. It appears that the correct chemical description of the global approach is the weakest link of the chain today. This arises mainly from the difficulty in either obtaining reliable gas phase and surface kinetic information and/or proposing the accurate chemical mechanisms evolving in the CVD reactor. Chemical models treating hundreds of gas phase and surface reactions affect the degree of accessibility and reliability of such models [2].

\section{APPROACH}

This paper presents a study involved in a systematic experimental and numerical approach -described elsewhere [3] - in order to propose tractable chemical models for the system $\mathrm{Si}-\mathrm{C}-\mathrm{H}$. In our systematic approach, we first study the CVD of the individual elemental constituents of $\mathrm{SiC}$, namely, silicon and carbon. Dilute silane $\left(\mathrm{SiH}_{4}\right)$ and methane $\left(\mathrm{CH}_{4}\right)$ in hydrogen are chosen as gaseous precursors for $\mathrm{CVD}$ of silicon and carbon in an effort to provide analogous chemical mechanisms and reaction pathways. The chemical mechanisms for the two systems are deliberately reduced to three reactions: one gaseous and two surface reactions as schematically described on figure 1 . An imaginary intermediate species $A_{m} H_{n}$ is included in the mechanism path. The identity and subsequent reactions of the imaginary intermediate species $\mathrm{A}_{m} \mathrm{H}_{n}$ will certainly affect the magnitude of the effective rate constants $\mathrm{k}^{*}$ and $\eta^{\prime}$. These effective species and rate constants created by our "lumping" strategy are expected to take into account the overall actual reactions.

\section{(1) National Research Council Resident Research Associate. Present address: LTPCM-ENSEEG, Domaine Universitaire, BP. 75, 38402 Saint-Martin d'Hères cedex, France}




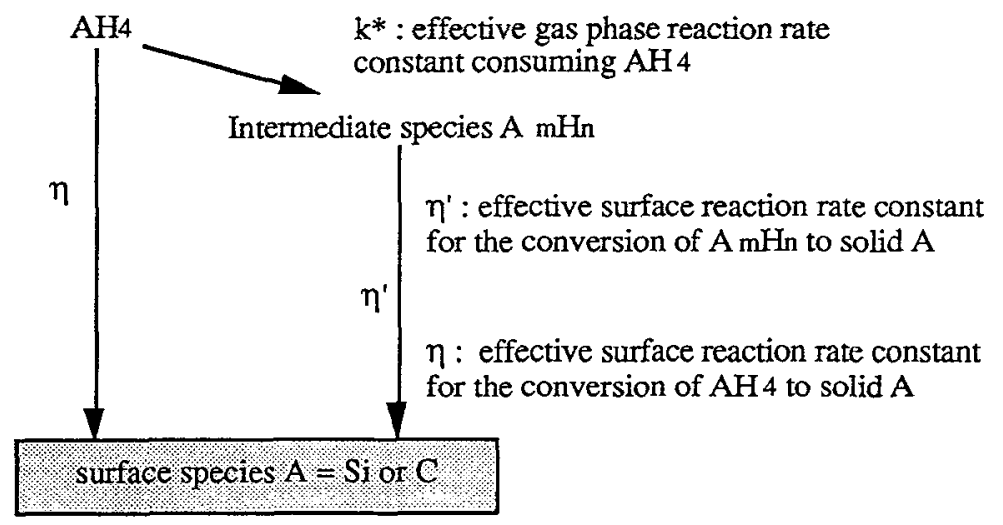

Figure 1. Chemical mechanism for CVD of $\mathrm{AH}_{4}$.

The finite-volume based computational code FLUENT 3.03 [4] is adopted to simulate the CVD reactor in a two-dimensional flow geometry. The reactor has well-characterized flow and thermal fields and is designed for variable deposition rates. It is a hot-wall, axial flow reactor schematically shown in figure 2.

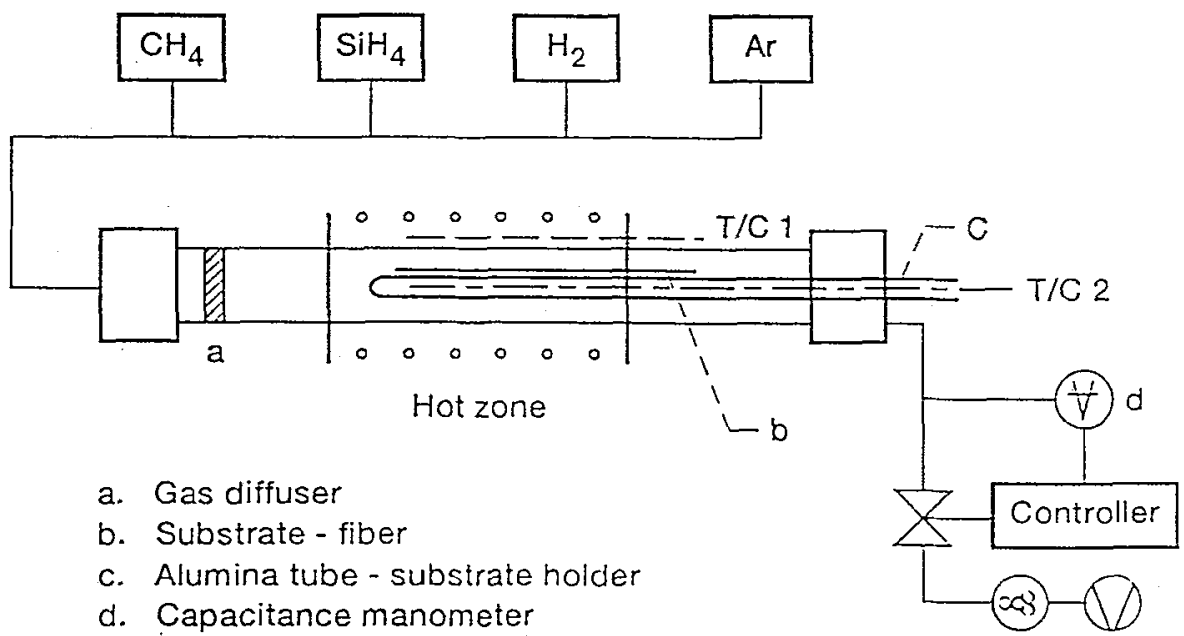

Figure 2. Schematic of the hot-wall, axial-flow horizontal CVD reactor.

It provides simultaneous variation in gas phase concentration and temperature. A thermocouple alumina tube $\left(O D=6.310^{-3} \mathrm{~m}\right)$ is installed in the center of the horizontal heated alumina reactor $\left(\mathrm{ID}=2.5410^{-2} \mathrm{~m}\right)$ and is used as substrate holder. Temperature profiles on the surface of the external alumina tube and inside the substrate holder, total pressure and inlet gas mass flows are measured. Deposition is done on Saphikon ${ }^{\mathrm{TM}}$ and Textron ${ }^{\mathrm{TM}}$ fibers, cemented on top of the centered alumina tube, as shown in figure 2. Prior to deposition, fibers are ultrasonically cleaned and then blown dry. Deposit film thickness is measured along the fiber by an optical method (Laser Mike ${ }^{\mathrm{TM}}$ ) using the shadow of a laser beam and verified by Scanning Electron Microscopy. For silicon CVD, two temperatures ("1000 and $1200^{\circ} \mathrm{C}^{\prime \prime}$ ) corresponding to the maximum of temperature profile of the furnace are selected. The concentration of silane is $0.3 \%$ by mole in hydrogen. The temperature " $1400^{\circ} \mathrm{C}$ " and methane concentration of $5 \%$ by mole in hydrogen are chosen for carbon CVD study. In both cases, total pressure is either $9.31 * 10^{4} \mathrm{~Pa}$ (700 Torr) -labeled AP- or $6650 \mathrm{~Pa}$ (50 Torr) -labeled LP. Total flow rate is kept constant at $1 \mathrm{slm}$ in all runs. For each conditions, at least two runs have been performed and uncertainties related to thickness measurement have been considered. 


\section{RESULTS AND DISCUSSION}

For the numerical calculations, we use the experimentally measured temperature profiles on the external wall and inside the substrate holder for each total pressure and gas flow rate. Geometry of the reactor is treated as axisymmetric. Because methane and silane are dilute in hydrogen, thermophysical and transport properties are calculated by treating the mixture as pure hydrogen. Reactions are considered on both external tube wall and substrate holder surfaces.

Temperature profiles at the surface of the substrate holder calculated from the experimental values for the "1000 and $1400^{\circ} \mathrm{C}$ " cases are presented with the corresponding experimental deposition rates in figures $3 \mathrm{a}$ and $3 \mathrm{~b}$, respectively. The temperature profiles are essentially independent of total pressure.
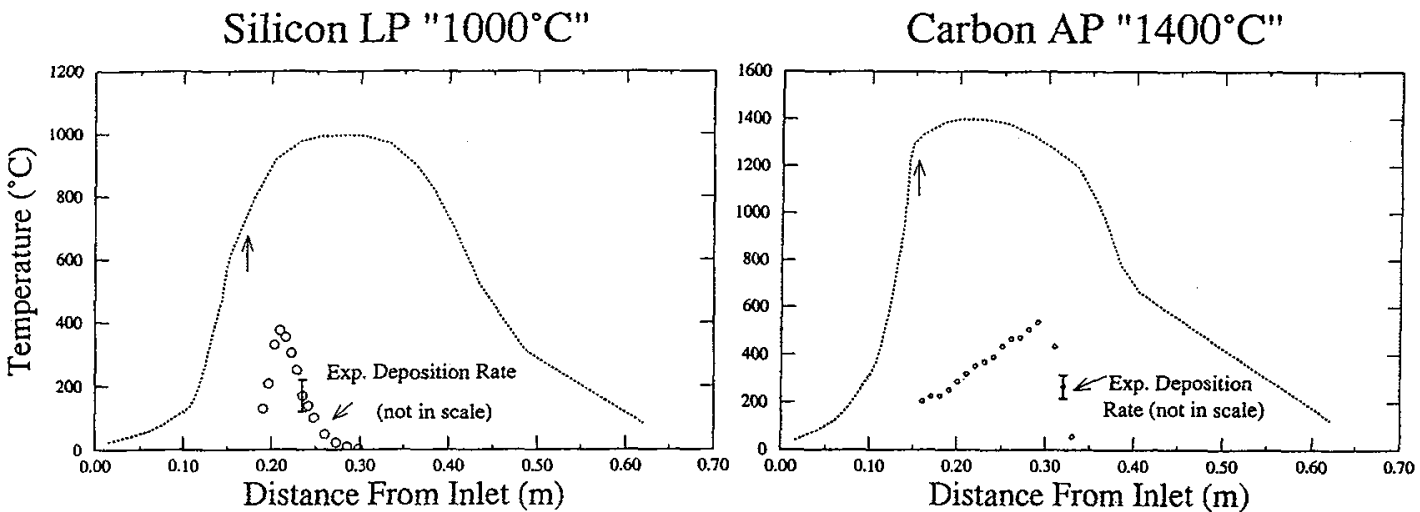

Figure 3. Calculated temperature profile and experimental deposition rate (not in scale) along the substrate. a) Silicon " $1000^{\circ} \mathrm{C}$ ", b) Carbon " $1400^{\circ} \mathrm{C}$ ".

For the case of carbon, there is no deposition when temperature is below $1300^{\circ} \mathrm{C}$ (see arrows in figure 3). For the case of silicon, deposition rate increases at around $750^{\circ} \mathrm{C}$, and drops because of silane depletion.

For carbon deposition, the considered gas phase and surface reactions are given as follows:

Gas phase: $\mathrm{CH}_{4} \rightarrow \mathrm{A}_{m} \mathrm{H}_{n}$ (R1) Surface: $\mathrm{CH}_{4} \rightarrow \mathrm{C}$ (R2) and $\mathrm{A}_{m} \mathrm{H}_{n} \rightarrow \mathrm{C}$ (R3).

Reaction 1 (R1) is an irreversible reaction. Different values for the reaction $R 1$ rate constant, listed in table 1, selected from the NIST Chemical Kinetics Database [5] and the literature review proposed by Warnatz [8] have been considered. Surface kinetics of reaction R2 and R3 are estimated using different sticking coefficients $\gamma$ in the equation: $\eta^{\prime}=(\gamma)(\mathrm{RT} / 2 \pi \mathrm{m})^{1 / 2}$, where $\mathrm{m}$ is the species molecular weight. Methane sticking coefficient has been reported to be equal to $5 \mathrm{E}-5$ [9] and lower [10].

\begin{tabular}{|c|c|c|c|c|c|}
\hline Reference & $\mathrm{A}_{\mathrm{m}} \mathrm{H}_{\mathrm{n}}$ & $\mathrm{M}$ & $\mathrm{A}\left(\mathrm{s}^{-1}\right)$ & $\beta$ & $\mathrm{E}$ (J/kgmol) \\
\hline Klotz [6], NIST & Unidentified & $\mathrm{N}_{2}$ & $1 \mathrm{E} 13$ & 0 & $4.28 \mathrm{E} 8$ \\
\hline Klotz [7], NIST & Unidentified & $\mathrm{H}_{2}$ & $1 \mathrm{E} 9$ & 0 & $2.43 \mathrm{E} 8$ \\
\hline Warnatz [8] & $\begin{array}{c}\mathrm{CH}_{3} \\
\text { forward reaction }\end{array}$ & - & $1 \mathrm{E} 15$ & 0 & $4.20 \mathrm{E} 8$ \\
\hline
\end{tabular}

Table 1. Reported rate constant $k^{*}$ for methane dissociation $\mathrm{CH}_{4} \rightarrow \mathrm{A}_{m} \mathrm{H}_{n}$, in diluent $\mathrm{M}$ $k^{*}=A T^{\beta} \exp (-E / R T)$. 
During the process of parameter optimization, methane sticking coefficient has been deliberately reduced to $1 \mathrm{E}-10$, which is consistent with Makarov and Pechik results [10]. The predicted values of C deposition using the values proposed by Klotz [7] pertaining to a hydrogen bath are much larger than the experimental ones, therefore the values proposed by Klotz [6] and Warnatz [8] have been used. Figures $4 \mathrm{a}$ and $4 \mathrm{~b}$ show the optimized predicted and experimental carbon deposition rates along the substrate under the conditions " $1400^{\circ} \mathrm{C}$ " $-\mathrm{LP}$ and " $1400^{\circ} \mathrm{C}$ " - AP, respectively.

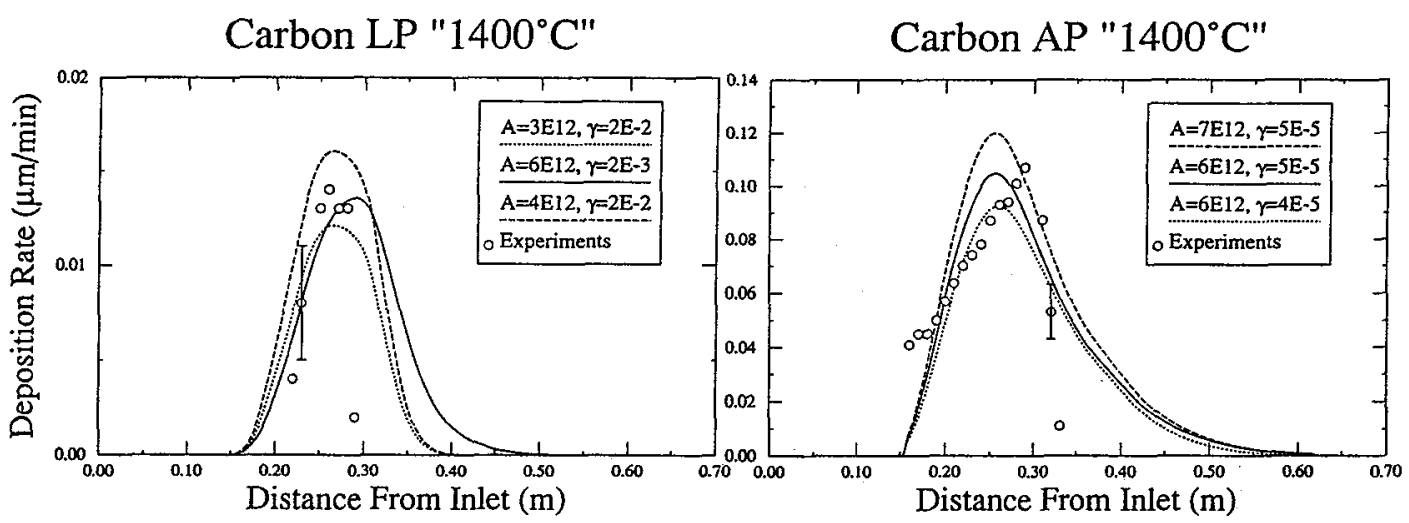

Figure 4. Predicted and experimental carbon deposition rates along the substrate under the conditions: a) " $1400^{\circ} \mathrm{C}$ ", LP b) " $1400^{\circ} \mathrm{C}$ ", AP. The error bars are representative of experimental uncertainties.

By varying $A$ (Reaction $R 1$ ) and $\gamma$ (Reaction $R 3$ ) the shape of the calculated deposition peak changes: $A$ and $\gamma$ have an effect on the maximum of the peak and its position, respectively. In both cases, AP and LP, the optimized A value is 2 orders of magnitude lower than the value recommended by Warnatz [8], which might be explained with two considerations: a) the value recommended by Warnatz is the forward reaction rate whereas our "lumped" value corresponds effectively to both forward and reverse reaction rates and b) the working pressure (50 or 700 Torr) belongs to the domain of reaction rate "fall-off" (decrease of the rate constant with pressure) for both forward and reverse reactions, as shown in figure 5 .
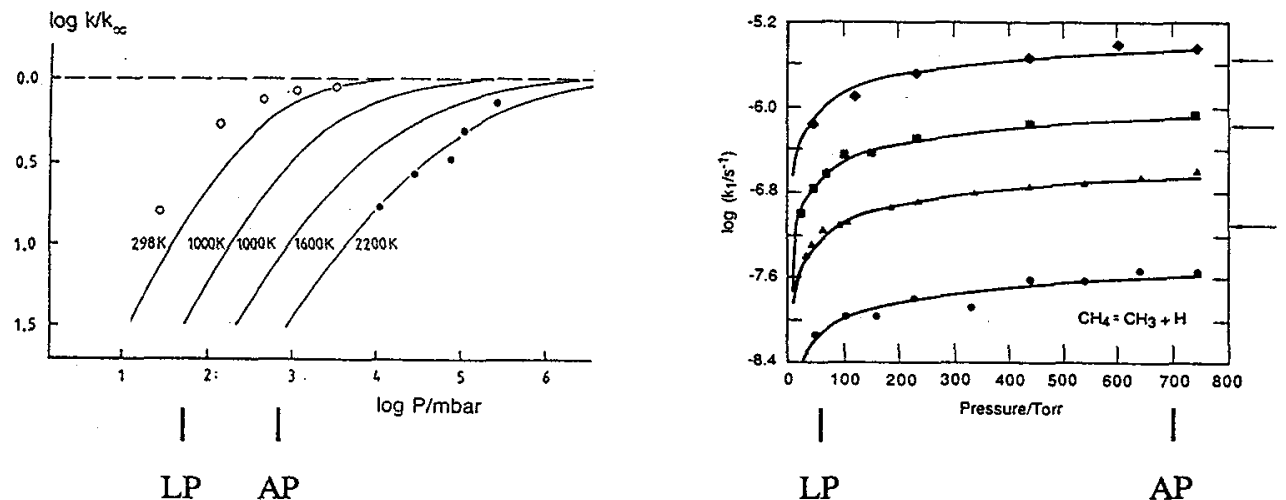

Figure 5. Fall-off curves for a) $\mathrm{CH}_{3}+\mathrm{H}->\mathrm{CH}_{4}$ and b) $\mathrm{CH}_{4}->\mathrm{CH}_{3}+\mathrm{H}$. Taken from [8] and [11]. 
For silicon deposition, the considered gas phase and surface reactions are given as follows: Gas phase: $\mathrm{SiH}_{4}<-\rightarrow \mathrm{SiH}_{2}+\mathrm{H}_{2}$ (R1) Surface: $\mathrm{SiH}_{4} \rightarrow \mathrm{Si}+2 \mathrm{H}_{2}$ (R2) and $\mathrm{SiH}_{2} \rightarrow>\mathrm{Si}+\mathrm{H}_{2}$ (R3). Reaction 1 (R1) is a reversible reaction. Two different values for the reaction R1 kinetics have been selected: one labeled "Model A"- is taken from Moffat and Jensen [12], $\left(\mathrm{k}_{\mathrm{f}}=6.1 \mathrm{E} 28 \mathrm{~T}^{-5} \exp \left(-2.461 \mathrm{E} 8 / \mathrm{RT}^{\mathrm{N}}\right) \mathrm{s}^{-1}\right.$ and $\mathrm{k}_{\mathrm{r}}=5.28 \mathrm{E} 21 \mathrm{~T}^{-4.44} \exp (-1.427 \mathrm{E} 7 / \mathrm{RT}) \mathrm{m}^{3} / \mathrm{kgmols}$, preArrhenius factor in $\left.\mathrm{J} / \mathrm{kgmol}\right)$, the second labeled "Model B" come from calculations made for higher temperature silane dissociation [13], $\left(\mathrm{k}_{\mathbf{f}}=\right.$ 4.07 E29 T-4.966 $\exp (-2.505 \mathrm{E} 8 / \mathrm{RT}) \mathrm{s}^{-1}$ and $\mathrm{k}_{\mathrm{r}}=6.65 \mathrm{E} 22 \mathrm{~T}^{-4.041} \exp (-1.3794 \mathrm{E} 7 / \mathrm{RT}) \mathrm{m}^{3} / \mathrm{kgmols}^{\mathrm{s}}$ preArrhenius factor in $\mathrm{J} / \mathrm{kgmol}$ ). For both models $\mathrm{A}$ and $\mathrm{B}$, the surface kinetics of reaction $\mathrm{R} 2$ is calculated from the sticking coefficient of silane given by Coltrin et al. [14] $(\gamma=5.37 \mathrm{E}-2 \exp (-9400 / \mathrm{T}))$. For reaction $\mathrm{R} 3$ the sticking coefficient for $\mathrm{SiH}_{2}$ is taken as unity. Figures $6 \mathrm{a}$ and $6 \mathrm{~b}$ show the predicted and experimental Si deposition rates under the conditions " $1000^{\circ} \mathrm{C}^{\prime \prime} \mathrm{LP}(6 \mathrm{a})$ and $\mathrm{AP}(6 \mathrm{~b})$, respectively.

Silicon LP " $1000^{\circ} \mathrm{C} "$

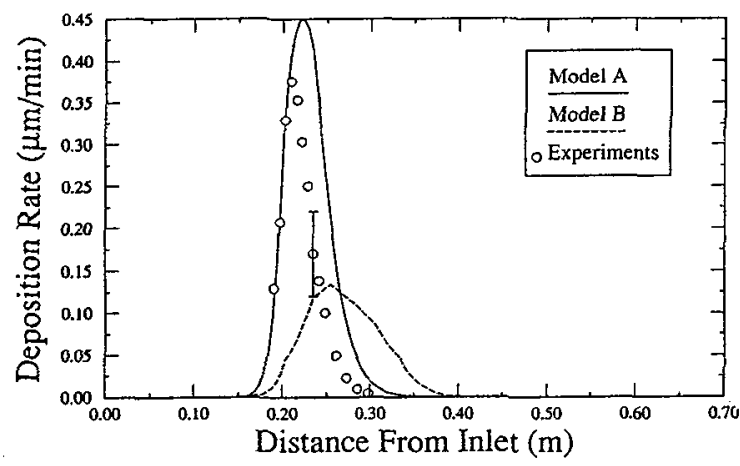

Silicon $\mathrm{AP} " 1000^{\circ} \mathrm{C} "$

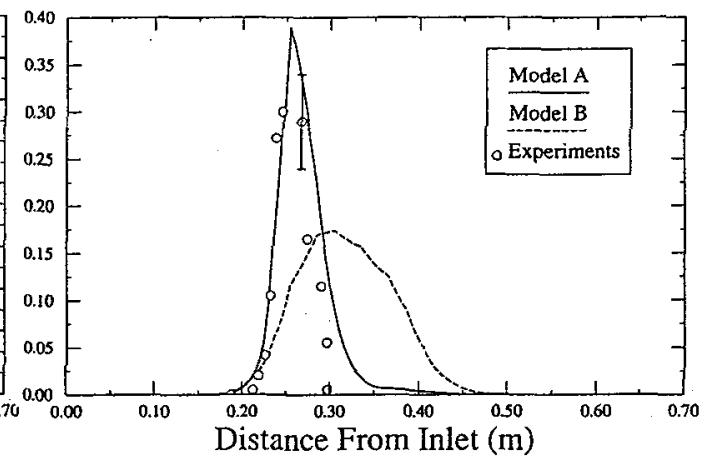

Figure 6. Predicted and experimental silicon deposition rates along the substrate under the conditions: a) " $1000^{\circ} \mathrm{C}$ ", LP, b) " $1000^{\circ} \mathrm{C}$ ", AP. The error bars are representative of experimental uncertainties.

In both cases Model A provides a good agreement with experimental results for the shape, position and magnitude of the deposition profile. Calculations performed with decreasing the temperature by $25^{\circ}$ (which is an acceptable error for temperature measurement) indicate a better agreement as shown in figure 7.

Silicon LP " $1000^{\circ} \mathrm{C} "$

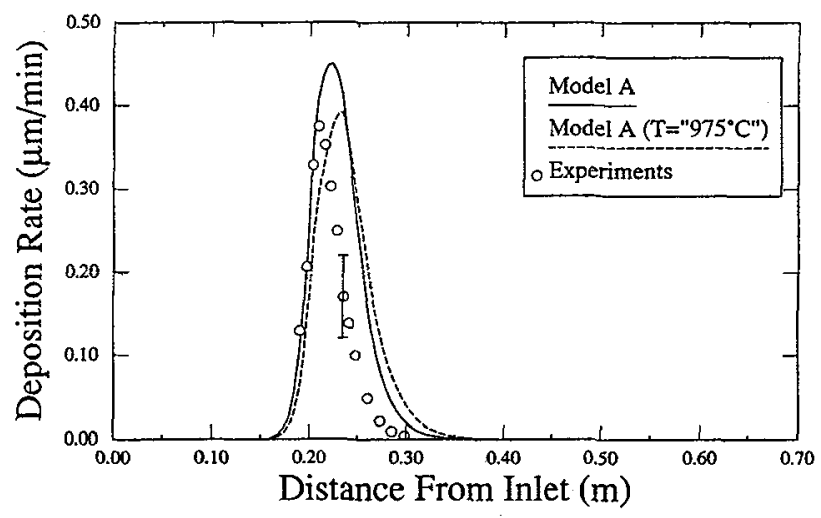

Figure 7: Predicted and experimental silicon deposition rates along the substrate under the conditions: $" 1000^{\circ} \mathrm{C} "$, LP. Model A T $=" 1000^{\circ} \mathrm{C} "$ and Model A T $=" 975^{\circ} \mathrm{C} "$. 
However, for the higher temperature " $1200^{\circ} \mathrm{C}$ " runs -displayed in figures $8 \mathrm{a}$ (LP) and $8 \mathrm{~b}$ (AP) -, it appears that Model B -as expected-is predicting the magnitude of the deposition peak better than Model A but fails for its position.

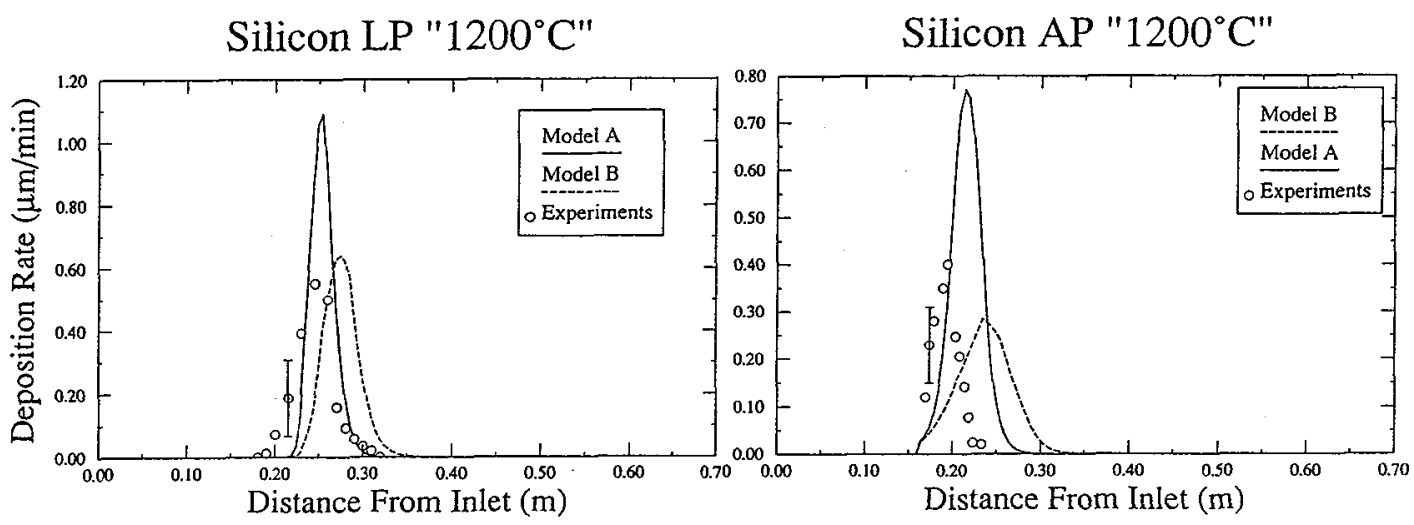

Figure 8. Predicted and experimental silicon deposition rates along the substrate under the conditions: a) " $1200^{\circ} \mathrm{C}$ ", LP, b) " $1200^{\circ} \mathrm{C}$ ", AP

Similar to the " $1000^{\circ} \mathrm{C}$ " cases, the effect of some experimental parameters has been investigated: a) temperature decrease of $200^{\circ} \mathrm{C}$ (figure $9 \mathrm{a}$ ), b) silane concentration reduced from $0.30 \%$ to $0.17 \%$ (figure $9 \mathrm{~b}$ ) and c) misplaced -by three $\mathrm{cm}$ - temperature profile measurement (figure 10). It is shown that these acceptable changes in boundary conditions would promote either of the two models.

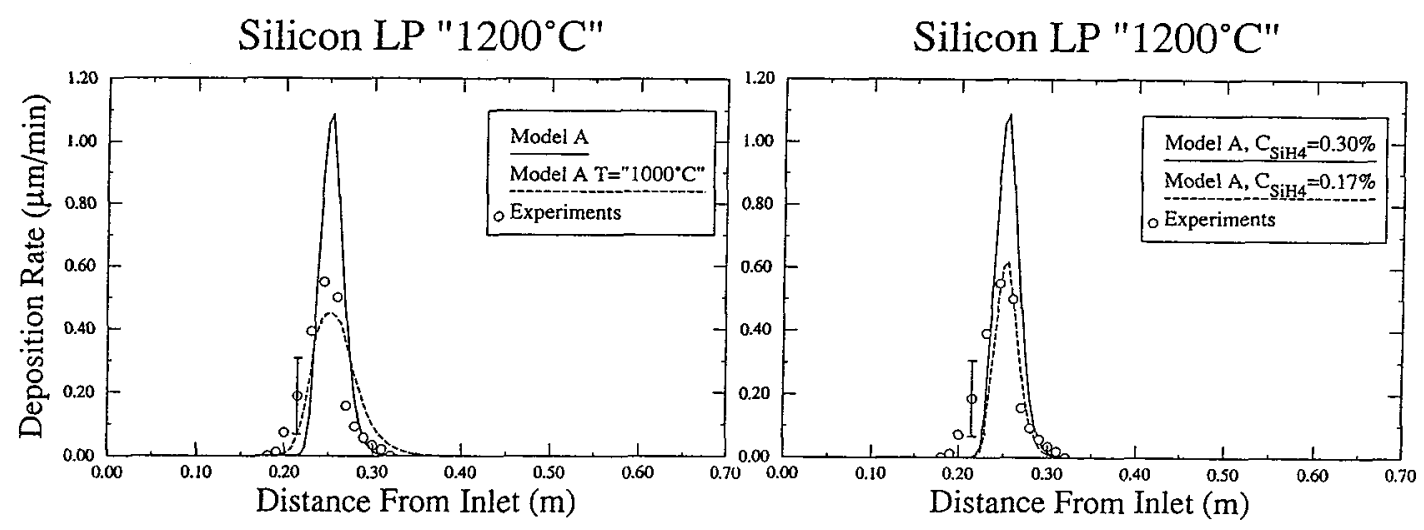

Figure 9. Predicted and experimental silicon deposition rates along the substrate under the conditions: " $1200^{\circ} \mathrm{C}$ ", LP. a) Model A change in T, b) Model A change in silane concentration. 


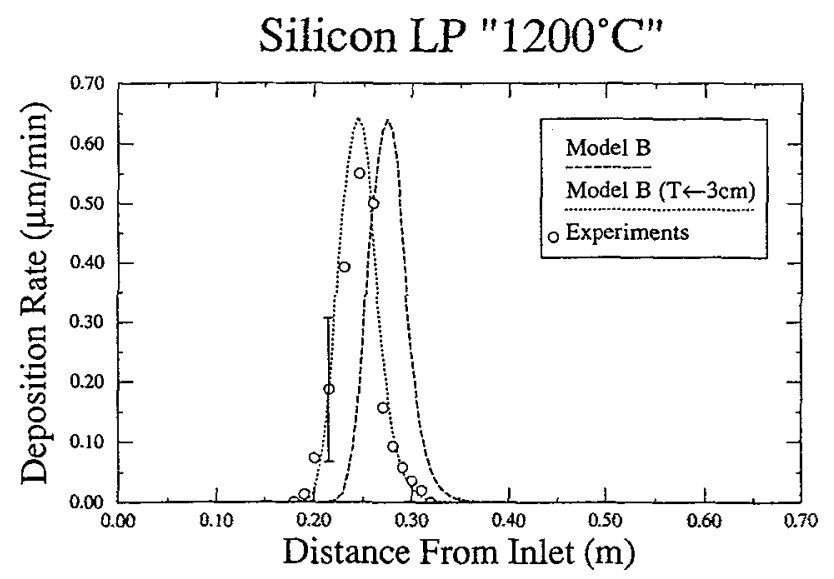

Figure 10. Predicted and experimental silicon deposition rates along the substrate under the conditions: " $1200^{\circ} \mathrm{C}$ ", LP. Model B temperature profile misplaced by $3 \mathrm{~cm}$.

\section{SUMMARY AND CONCLUSION}

A systematic experimental and numerical approach is designed to develop tractable chemical models for CVD applications. The model is assumed to consist of lumped chemical reactions, one in gas phase and two at the surface. Initial testing of the approach is carried out by using the chemical kinetic parameters currently available in the literature for silicon and carbon deposition from silane and methane dilute in hydrogen. Comparison of the model performances with our experiments show that adjustments are necessary to the kinetic parameters for better predictions. Optimized tractable models consistent with literature data are proposed.

\section{REFERENCES}

[1] JENSEN K.F., in Microelectronics Processing: Chemical Engineering Aspects, D.W. Hess, K.F. Jensen, American Chemical Society, (1989) 199.

[2] GOKOGLU S.A., Mater. Res. Symp. Proc. 250 (1991) 17.

[3] BLANQUET E. and GOKOGLU S.A., 12th International Conf. on CVD, Hawaii, 1993, In press.

[4] FLUENT Version 3.02 Manual, Fluent, Inc., Lebanon, $\mathrm{NH}$.

[5] NIST Chemical Kinetics Database, Version 4.0 (1992).

[6] KLOTZ H.D. et al., Z. Phys. Chem. (Leipzig) 266 (1985) 101.

[7] KLOTZ H.D., DROST D H. and SPANGENBERG H.J., Z. Phys. Chem. 261 (1980) 201.

[8] WARNATZ J., in Combustion Chemistry: Rate Coefficients in the C/H/O System, W.C. Gardiner, Jr., p 197, Springer-Verlag.

[9] ANNEN K.D., STINESPRING C.D., KUCZMARSKI M.A. and POWELL J.A., J. Vac. Sci. Technol. A 83 (1990) 2970.

[10] MAKAROV .K.I.and PECHIK V. K., Carbon 12 (1974) 391.

[11] STEWART P. H., SMITH G.P. and GOLDEN D.M., International Journal of Chemicals Kinetics 21 (1989) 923.

[12]MOFFAT H.K. and JENSEN K.F., J. Electrochem. Soc. 135 (1988) 459.

[13] MOFFAT H. K., Private Communcation.

[14] COLTRIN M.E., KEE R.J. and MILLER J.A., J. Electrochem. Soc. 133 (1986) 1206. 